\title{
Associations of Upper Arm and Thigh Circumferences with Dementia and Depression in Korean Elders
}

\author{
Yong-Seong Lee, Sang-Dae Kim, Hee-Ju Kang, Sung-Wan Kim, \\ II-Seon Shin, Jin-Sang Yoon, and Jae-Min Kim ${ }^{凶}$ \\ Department of Psychiatry, Chonnam National University Medical School, Gwangju, Republic of Korea
}

\begin{abstract}
Objective Previous studies have reported an association between weight loss and cognitive impairment. Changes in anthropometric measurements, such as arm and thigh circumferences, are associated with body mass changes and physical activity. Our aim was to investigate the association of upper arm and thigh circumferences with dementia and depression in the community-dwelling elderly population.

Methods In total, 2,498 community residents aged 65 years or over were clinically assessed for dementia using the Korean version of the Community Screening Interview for Dementia. Depression was also assessed using the Korean version of the Geriatric Mental State Schedule B3. Arm and thigh circumferences were measured. Complex sample logistic regression was performed to evaluate associations of changes in anthropometric measurements with dementia/depression after controlling for other covariates.

Results In the adjusted analyses, there was an independent association between dementia and arm circumference (OR=1.12; 95\% $\mathrm{CI}=1.06-1.19)$. This association was significant in the females $(\mathrm{OR}=1.12 ; 95 \% \mathrm{CI}=1.05-1.19)$ but not in males $(\mathrm{OR}=1.07 ; 95 \% \mathrm{CI}=0.93-$ 1.28). The association between dementia and thigh circumference was not significant in the adjusted analysis $(\mathrm{OR}=1.03$; $95 \% \mathrm{CI}=0.99-$ 1.07). No significant association was found between either upper arm or thigh circumference and depression.

Conclusion In the older female Korean population, decreased upper arm circumference was associated with dementia and may represent a biological marker for this condition. This association may be explained by nutritional deficits or decreased physical activity.
\end{abstract}

Psychiatry Investig 2017;14(2):150-157

Key Words Arm, Thigh, Anthropometry, Dementia, Depression.

\section{INTRODUCTION}

Many older people suffer from mental illnesses, such as dementia and depression. Dementia, a serious mental illness in many developed countries, especially Korea, ${ }^{1}$ has a high prevalence and a progressive, irreversible course in older adults. ${ }^{2}$ However, there is controversy over how to properly manage dementia, and many studies have reported that prevention of dementia is the most important element.

To date, many risk factors for dementia are known. Vascular risk factors, such as hypertension, diabetes, and obesity, are the

Received: June 27, 2016 Revised: August 3, 2016

Accepted: August 29, 2016 Available online: November 2, 2016

$\triangle$ Correspondence: Jae-Min Kim, MD, PhD

Department of Psychiatry, Chonnam National University Medical School, 160 Baekseo-ro, Dong-gu, Gwangju 61469, Republic of Korea

Tel: +82-62-220-6143, Fax: +82-62-225-2351, E-mail: jmkim@chonnam.ac.kr

(a) This is an Open Access article distributed under the terms of the Creative Commons Attribution Non-Commercial License (http://creativecommons.org/licenses/by$\mathrm{nc} / 4.0$ ) which permits unrestricted non-commercial use, distribution, and reproduction in any medium, provided the original work is properly cited. most important. Conversely, higher educational status and participation in complex work, social engagements, mentally stimulating activities, and regular physical activity have been shown to have protective properties in the context of dementia. ${ }^{3,4}$ Interestingly, many researchers have observed that demented patients have a thin body type. ${ }^{5}$ Recent studies have revealed that weight loss in dementia is associated with increased morbidity and mortality. ${ }^{6,7}$ Although obesity is a risk factor for dementia, ${ }^{8}$ prospective studies have revealed that weight loss occurs several years before the clinical onset of the disease, ${ }^{9}$ accelerating in the 3-6 years leading up to diagnosis ${ }^{10}$ and throughout the course of the disorder. ${ }^{11}$ Additionally, sarcopenia, which is a loss of skeletal muscle mass strongly related to reduced physical activity, may be exaggerated in people with dementia. ${ }^{12,13}$ It has also been reported that small upper arm circumference is associated with cognitive impairment. . $^{14,15}$ Upper arm circumference, which is related to skeletal muscle mass, is used as an indicator of nutritional status and lower levels of physical activity. Furthermore, research in Taiwan 
revealed that age-related loss of skeletal muscle mass may be significantly associated with sarcopenia. ${ }^{16}$

Depression is highly prevalent in the elderly and has a negative impact on quality of life. ${ }^{17}$ Decreased appetite is a key symptom of depression that influences weight loss. Depressive symptoms are more frequently found among people who have a nutritional imbalance, which is usually a consequence of unintended weight loss, ${ }^{18}$ reduced food intake, and bad dietary habits. ${ }^{19}$ Recent studies have suggested that depression in the elderly can be predicted by modifiable factors, such as decreased physical activity or impaired nutritional status. ${ }^{20}$ Muscle mass is a marker of nutritional status; however, there are few reports concerning the association between depression and muscle mass.

There are many tools currently available to establish the nutritional status and level of physical activity of elderly people. Anthropometric testing is non-invasive, cost-efficient, and effective in population-based studies. ${ }^{21}$ The World Health Organization has gathered international anthropometric data on health, nutrition, and well-being, emphasizing the significance of the phenotypic impact of aging, senility, and associated diseases. ${ }^{22}$ Wijnhoven and colleagues revealed that midupper arm circumference measurement is a feasible and valid anthropometric measurement for use in older people..$^{23}$ It is, therefore, valuable to clarify the relationship between lean body mass and dementia/depression.

Previously, many efforts have been made to reveal the biomarkers of dementia and depression; however, no associations between upper arm or thigh circumference and dementia or depression have been reported. Based on data obtained from a survey of a Korean elderly population, we investigated upper arm and thigh circumferences as factors potentially associated with dementia and depression.

\section{METHODS}

\section{Study population}

Study data were acquired from a larger prospective community survey concerning late-life psychiatric morbidity that was conducted between 2001 and 2006 in collaboration with the 10/66 International Dementia Research Program in Developing Countries. ${ }^{24}$ The people included in the study were all over the age of 65 years; residents of Gwangju, South Korea; on the national registration list; and voluntary participants. The data for this study were acquired in 2006, and letters containing a description of the study were delivered to all of the potential participants before the study was performed. Research nurses, who were trained and supervised by the project psychiatrist, visited the homes of all participants to register them in the study. The study was approved by the
Chonnam National University Hospital Institutional Review Board, and all participants or their family members provided formal written informed consent.

\section{Diagnosis of dementia and depression}

The participants completed the Korean version of the Geriatric Mental State Schedule B3 (GMS B3-K) ${ }^{25}$ and the Korean version of the Community Screening Interview for Dementia- (CSID-K). ${ }^{26}$ The GMS B3 is a structured diagnostic interview that is widely used internationally with the Automated Geriatric Examination for Computer Assisted Taxonomy (AGECAT) algorithm, which provides individual diagnoses of mental illnesses such as depression. The GMS B3 was translated into Korean according to a formal standardization process. ${ }^{25}$ Using the results derived from the three above measures, a dementia diagnosis was made according to a $10 / 66$ dementia diagnostic algorithm. ${ }^{24}$ This provides a tool that diagnoses the dementia as a whole thereby unable to classify the dementia by subtypes such as 'Dementia of the Alzheimer's type' or 'vascular dementia. Depression was diagnosed with the GMS B3 using a 'stage one' (non-hierarchical) confidence level of three or above in the AGECAT algorithm. The instrument and algorithm were developed 1 month before the interview to ensure they were able to identify the depressive states that are currently considered severe enough to require clinical invention. Therefore, the 'case-level depression' assessment was designed to be more extensive than the major depressive disorder criteria in the Diagnostic and Statistical Manual of Mental Disorders, Fourth Edition (DSMIV $)^{27}$ in that symptoms ranging from moderate to severe were included.

\section{Measurement of mid-arm and thigh circumference}

Anthropometric measurements were taken using a tape measure and estimated to the nearest centimeter. Upper arm circumference was measured at the thickest part of the upper arm on the dominant side. Thigh circumference was measured at the thickest part of the right thigh.

\section{Covariates}

Covariates potentially associated with the relationship between dementia or depression and anthropometric measurements were evaluated. ${ }^{28}$ Data on sociodemographic variables, such as age, gender, marital status, education, religion, past and current occupation, and living situation, were collected from participants and family members. In terms of the anthropometric measurements, information on height, physical activity, and number of physical illnesses was obtained by selfreport and corroborated by a family member when possible. Disability was assessed using the Korean version of the World 
Health Organization Disability Assessment Schedule (WHODAS II). ${ }^{29}$

\section{Statistical analyses}

Chi-square and t-tests were used for the descriptive analyses of dementia and depression. The prevalences of dementia and depression, with 95\% confidence intervals (95\% CIs), are presented as quartiles of the mean upper arm and thigh circumferences. Complex sample logistic regression was performed to determine associations of anthropometric measurements (1-centimeter intervals) with dementia and depression after controlling for other covariates. Adjustments were as follows: Model 1 was unadjusted; Model 2 was adjusted for age, gender, and educational level; Model 3 was further adjusted for WHODAS score, depression status and dementia status plus the variables in Model 2. Data analysis was performed using Statistical Package for the Social Sciences (SPSS 21; SPSS Inc., Chicago, IL, USA).

\section{RESULTS}

\section{Recruitment}

The study included 2,498 community residents aged 65 or older; 1,544 (61.8\%) of the participants were female, and the mean age of the sample was 73.24 (standard deviation, $\mathrm{SD}=6.35)$ years. In total, $271(10.8 \%)$ were diagnosed with dementia, and 295 (11.8\%) had case-level depression.

\section{Association between participant characteristics and dementia or depression}

The participant characteristics associated with dementia and depression are presented in Table 1. Dementia and depression were associated with being older, female, less educated, unmarried, and currently employed, as well as with renting, having a previous manual occupation, not engaging in physical activity, having many physical illnesses, and having a more severe disability (all $\mathrm{p}<0.001$ ). There were no differences in religion or height between the dementia and non-dementia groups.

Depression was associated with being female $(\mathrm{p}<0.001)$, having less education $(p<0.01)$, being unmarried $(p<0.001)$, having no religion ( $\mathrm{p}<0.01)$, renting $(\mathrm{p}<0.001)$, having a manual occupation in the past $(\mathrm{p}<0.001)$, being currently employed ( $\mathrm{p}<0.05)$, not being physically active $(\mathrm{p}<0.001)$, having many physical illnesses $(\mathrm{p}<0.001)$, and suffering from a more severe disability $(\mathrm{p}<0.001)$. No significant differences were found with respect to older age or height between the depressed and non-depressed groups.

\section{Prevalence of dementia and depression by upper arm and thigh circumferences}

Figure 1 shows the prevalence rates of dementia and depression for upper arm and thigh circumference quartiles. In the case of upper arm circumference, the prevalence rates of depression were $20.3 \%, 10.3 \%, 6.7 \%$, and $6 \%\left(\chi^{2}=81.71\right.$; $\mathrm{p}<0.001$ ) for each mean arm circumference quartile, from lowest to highest. The prevalence rates of dementia by thigh circumference were $20.7 \%, 9.7 \%, 6.3 \%$, and 5.6\% $\left(\chi^{2}=100.54\right.$; $\mathrm{p}<0.001$ ), from lowest to highest circumference quartile. For upper arm circumference, the prevalence rates of depression were $12.4 \%, 11.6 \%, 10.9 \%$, and $12.3 \%\left(\chi^{2}=0.902 ; \mathrm{p}=0.825\right)$ for each mean arm circumference quartile, from lowest to

Table 1. Characteristics of study participants by dementia and depression status

\begin{tabular}{|c|c|c|c|c|c|c|}
\hline & \multicolumn{3}{|c|}{ Dementia analysis } & \multicolumn{3}{|c|}{ Depression analysis } \\
\hline & $\begin{array}{l}\text { No dementia } \\
(\mathrm{N}=2278)\end{array}$ & $\begin{array}{c}\text { Dementia } \\
(\mathrm{N}=270)\end{array}$ & $\mathrm{p}$ & $\begin{array}{l}\text { No depression } \\
\quad(\mathrm{N}=2204)\end{array}$ & $\begin{array}{c}\text { Depression } \\
(\mathrm{N}=294)\end{array}$ & $\mathrm{p}$ \\
\hline Age, years (SD) & $72.6(6.0)$ & $78.29(6.0)$ & $<0.001$ & $73.2(6.4)$ & $73.5(6.2)$ & 0.96 \\
\hline Gender (female), N (\%) & $1,317(57.8)$ & $227(84.1)$ & $<0.001$ & $1,314(59.6)$ & $227(77.2)$ & $<0.001$ \\
\hline Education years (SD) & $6.4(5.2)$ & $1.7(3.3)$ & $<0.001$ & $6.0(50.3)$ & $4.5(4.5)$ & $<0.01$ \\
\hline Married, N (\%) & $1,364(59.9)$ & $62(23.0)$ & $<0.001$ & $1,299(58.9)$ & $127(43.2)$ & $<0.001$ \\
\hline Religion (have), N (\%) & $1,489(65.4)$ & $179(66.3)$ & 0.86 & $1,450(65.8)$ & $218(74.1)$ & $<0.01$ \\
\hline Accommodation (rented), N (\%) & $396(17.4)$ & $93(34.4)$ & $<0.001$ & $409(18.6)$ & $80(27.2)$ & $<0.001$ \\
\hline Past occupation (manual), N (\%) & $1,649(72.4)$ & $256(94.8)$ & $<0.001$ & $1,651(74.9)$ & $254(86.4)$ & $<0.001$ \\
\hline Current occupation (no), N (\%) & $1,979(86.9)$ & $261(96.7)$ & $<0.001$ & $1,965(89.2)$ & $275(93.5)$ & $<0.05$ \\
\hline Physical activity (non-active), N (\%) & $656(28.8)$ & $170(63.0)$ & $<0.001$ & $651(29.5)$ & $175(59.5)$ & $<0.001$ \\
\hline Number of physical illness (SD) & $2.4(1.7)$ & $3.2(1.8)$ & $<0.001$ & $2.6(1.7)$ & $3.3(1.8)$ & $<0.001$ \\
\hline WHODAS (SD) & $30.2(23.4)$ & $51.6(22.9)$ & $<0.001$ & $31.2(23.9)$ & $42.0(24.5)$ & $<0.001$ \\
\hline Height, cm (SD) & $155.7(10.2)$ & $157.7(10.9)$ & 0.10 & $155.8(10.3)$ & $156.6(9.8)$ & 0.75 \\
\hline
\end{tabular}

p-values by $\chi^{2}$ and t-tests. WHODAS: World Health Organization Disability Assessment Schedule 
highest. The prevalence rates of depression by thigh circumference were $15.1 \%, 12.2 \%, 11 \%$, and $8.6 \%\left(\chi^{2}=14.1 ; \mathrm{p}=0.003\right)$, from lowest to highest circumference quartile.

\section{Association of participant characteristics with upper arm and thigh circumferences}

Associations between participant characteristics and upper arm or thigh circumference are shown in Table 2. Small upper arm circumference was associated with older age, lower educational level, unmarried status, renting, unemployment, not engaging in physical activity, and lower WHODAS scores. Small thigh circumference was associated with older age, female gender, lower educational level, unmarried status, renting, a non-manual past occupation, unemployment, not engaging in physical activity, many physical illnesses, and lower WHODAS scores.

\section{Multivariate associations with dementia and depression}

Total and gender-stratified multivariate analyses of upper arm and thigh circumferences with dementia are summarized in Table 3. For upper arm circumference, the unadjusted odds ratio (OR) for dementia was 1.26 (OR=1.26; 95\% $\mathrm{CI}=1.20-1.33)$. The association remained significant but weakened after other variables were added ( $\mathrm{OR}=1.12 ; 95 \%$ $\mathrm{CI}=1.06-1.19)$. In a separate analysis, the association disappeared in males after adjusting for age and educational level.
In contrast, a significant association between dementia status and upper arm circumference remained in females even after adjusting for WHODAS score and depression status (OR= 1.12; 95\% CI=1.05-1.19). The association between dementia and thigh circumference was less significant than that between dementia and upper arm circumference $(\mathrm{OR}=1.03$; 95\% CI= 0.99-1.07). The association was also no longer significant following gender stratification. The same analyses were performed for depression (Table 4). Neither upper arm circumference nor thigh circumference had significant associations with depression.

\section{DISCUSSION}

Using large samples, we investigated associations of upper arm and thigh circumferences with dementia and depression. In summary, dementia was associated with smaller upper arm circumference, especially in women. Thigh circumference was also associated with dementia, but to a lesser extent. In contrast, there was no significant association between depression and upper arm or thigh circumference.

A previous study revealed that small upper arm circumference was associated with dementia in low- and middle-income countries. ${ }^{15}$ Small upper arm circumference is known to be associated with weight loss, nutritional deficiency, and decreased physical activity. We identified relationships between these characteristics and dementia. The relevance of weight
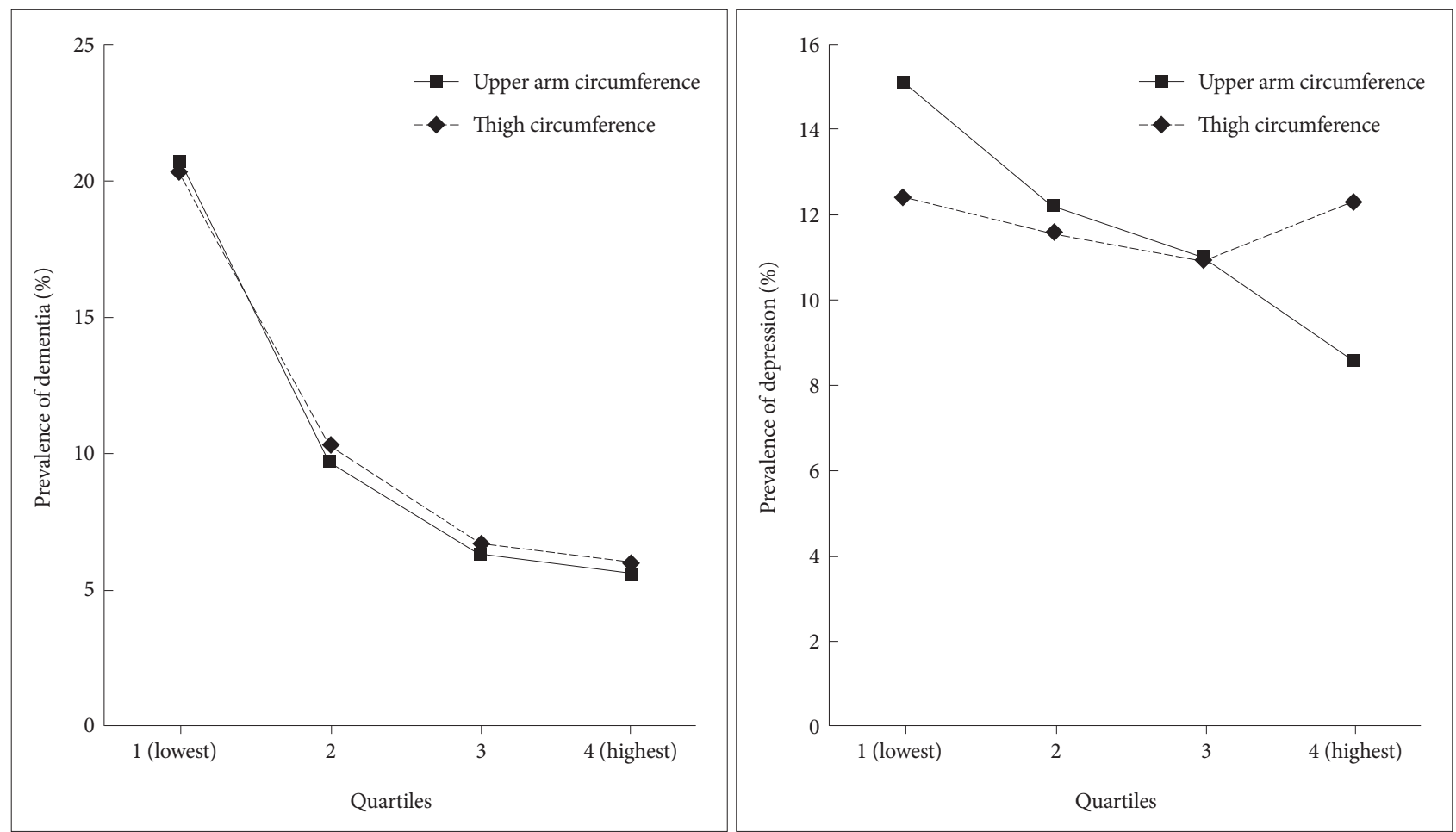

Figure 1. Prevalence rates of dementia and depression by upper arm and thigh circumference quartiles. 
loss to dementia is still uncertain, but several prospective studies have shown that weight loss begins and accelerates prior to the clinical onset of dementia, and associations with structural brain changes have been reported; for example, brain atrophy is associated with less lean mass in participants with earlystage dementia. ${ }^{30}$ Early neurodegenerative changes may influence feelings of hunger and fullness and the homeostatic control of energy consumption. There are two potential explanations for this: 1) the serotonin level decreases in the lat- eral hypothalamus, as demonstrated in cases of Alzheimer's dementia; ${ }^{31}$ or 2 ) weight loss or changes in body composition are the result of a stress response related to the deterioration of the brain function. ${ }^{32}$ Excessive weight loss increases brain atrophy. For example, infection can lead to malabsorption, which, in turn, causes deficiency syndromes. Additionally, changes in insulin sensitivity or carbohydrate metabolism disorders arise alongside or trigger neurodegeneration. ${ }^{33}$

Decreased upper arm circumference is correlated with ag-

Table 2. Associations with upper arm and thigh circumference

\begin{tabular}{|c|c|c|c|c|c|c|}
\hline \multirow{2}{*}{ Characteristic } & & \multirow{2}{*}{$\mathrm{N}$} & \multicolumn{2}{|c|}{ Upper arm circumference } & \multicolumn{2}{|c|}{ Thigh circumference } \\
\hline & & & Mean $(\mathrm{SD}) \mathrm{cm}$ & $\mathrm{p}$ & Mean $(\mathrm{SD}) \mathrm{cm}$ & $\mathrm{p}$ \\
\hline \multirow[t]{2}{*}{ Age, years } & $65-74$ & 1,539 & $27.1(2.9)$ & $<0.001$ & $33.6(4.6)$ & $<0.001$ \\
\hline & $75+$ & 959 & $25.8(4.0)$ & & $31.7(5.0)$ & \\
\hline \multirow[t]{2}{*}{ Gender } & Men & 954 & $26.6(3.4)$ & 0.475 & $34.4(4.6)$ & $<0.001$ \\
\hline & Women & 1,544 & $26.5(3.5)$ & & $31.9(4.8)$ & \\
\hline \multirow[t]{2}{*}{ Education, years } & 0 & 777 & $25.9(4.2)$ & $<0.001$ & $31.4(5.2)$ & $<0.001$ \\
\hline & $1+$ & 1,721 & $26.9(3.0)$ & & $33.5(4.6)$ & \\
\hline \multirow[t]{2}{*}{ Marital status } & Married & 1,426 & $26.9(3.0)$ & $<0.001$ & $33.7(4.5)$ & $<0.001$ \\
\hline & Not married & 1,072 & $26.2(3.9)$ & & $31.6(5.0)$ & \\
\hline \multirow[t]{2}{*}{ Religion } & Have & 1,668 & $26.7(3.4)$ & 0.138 & $32.7(4.7)$ & 0.083 \\
\hline & No & 830 & $26.4(3.5)$ & & $33.1(5.1)$ & \\
\hline \multirow[t]{2}{*}{ Accommodation } & Owned & 2,009 & $26.7(3.3)$ & 0.006 & $33.0(4.9)$ & $<0.001$ \\
\hline & Rented & 489 & $26.2(3.8)$ & & $32.0(4.8)$ & \\
\hline \multirow[t]{2}{*}{ Past occupation } & Non-manual & 593 & $26.8(2.9)$ & 0.076 & $34.2(3.9)$ & $<0.001$ \\
\hline & Manual & 1,905 & $26.5(3.6)$ & & $32.4(5.0)$ & \\
\hline \multirow[t]{2}{*}{ Current occupation } & Have & 258 & $27.0(2.9)$ & 0.042 & $34.0(4.6)$ & $<0.001$ \\
\hline & No & 2,240 & $26.5(3.5)$ & & $32.7(4.9)$ & \\
\hline \multirow[t]{2}{*}{ Physical activity } & Active & 1,672 & $26.7(3.5)$ & 0.011 & $33.2(4.6)$ & $<0.001$ \\
\hline & Non-active & 826 & $26.3(3.3)$ & & $32.1(5.4)$ & \\
\hline \multirow[t]{2}{*}{ Number of physical illness } & $0-1$ & 810 & $26.8(3.9)$ & 0.058 & $33.5(4.9)$ & $<0.001$ \\
\hline & $2+$ & 1,688 & $26.5(3.2)$ & & $32.5(4.8)$ & \\
\hline \multirow[t]{2}{*}{ WHODAS } & 0 & 482 & $27.0(3.5)$ & 0.005 & $33.9(4.3)$ & $<0.001$ \\
\hline & $1+$ & 2,016 & $26.5(3.4)$ & & $32.6(4.9)$ & \\
\hline \multirow[t]{2}{*}{ Height, cm } & 160 & 1,593 & $26.7(3.5)$ & 0.082 & $32.9(4.9)$ & 0.307 \\
\hline & $160+$ & 915 & $26.4(3.4)$ & & $32.7(4.9)$ & \\
\hline
\end{tabular}

p-values by $\chi^{2}$ and t-tests. WHODAS: World Health Organization Disability Assessment Schedule

Table 3. Multivariate associations of upper arm and thigh circumference with dementia

\begin{tabular}{cccccccc}
\hline & \multicolumn{3}{c}{ Upper arm circumference } & & \multicolumn{3}{c}{ Thigh circumference } \\
\cline { 2 - 3 } & Total $(\mathrm{N}=2498)$ & $\operatorname{Men}(\mathrm{N}=954)$ & Women $(\mathrm{N}=1544)$ & & Total $(\mathrm{N}=2498)$ & Men $(\mathrm{N}=954)$ & Women $(\mathrm{N}=1544)$ \\
\hline Model 1 & $1.26(1.20-1.33) \ddagger$ & $1.23(1.09-1.40)^{\dagger}$ & $1.27(1.20-1.34)^{\ddagger}$ & & $1.20(1.15-1.24)^{\ddagger}$ & $1.22(1.11-1.33)^{\ddagger}$ & $1.14(1.10-1.20)^{\ddagger}$ \\
Model 2 & $1.11(1.06-1.18)^{\ddagger}$ & $1.13(0.99-1.29)$ & $1.11(1.05-1.18)^{\dagger}$ & & $1.05(1.01-1.09)^{*}$ & $1.14(1.04-1.25)^{\dagger}$ & $1.03(0.99-1.07)$ \\
Model 3 & $1.12(1.06-1.19) \ddagger$ & $1.10(0.95-1.26)$ & $1.12(1.05-1.19)^{\ddagger}$ & & $1.03(0.99-1.07)$ & $1.06(0.97-1.17)$ & $1.02(0.98-1.06)$ \\
\hline
\end{tabular}

${ }^{*} \mathrm{p}<0.05,{ }^{\dagger} \mathrm{p}<0.01,{ }^{\ddagger} \mathrm{p}<0.001$ by complex sample logistic regression. Model 1=Unadjusted, Model 2=Model 1+age, gender and education, Model 3=Model 2+WHODAS score and depression status. WHODAS: World Health Organization Disability Assessment Schedule 
Table 4. Multivariate associations of upper arm and thigh circumference with depression

\begin{tabular}{ccccccccc}
\hline & \multicolumn{3}{c}{ Upper arm circumference } & & \multicolumn{3}{c}{ Thigh circumference } \\
\cline { 2 - 3 } & Total $(\mathrm{N}=2498)$ & Men $(\mathrm{N}=954)$ & Women $(\mathrm{N}=1544)$ & & Total $(\mathrm{N}=2498)$ & & Men $(\mathrm{N}=954)$ & Women $(\mathrm{N}=1544)$ \\
\hline Model 1 & $1.01(0.96-1.05)$ & $1.03(0.93-1.14)$ & $1.00(0.95-1.05)$ & & $1.06(1.03-1.09) \ddagger$ & $1.09(1.01-1.16)^{\dagger}$ & $1.02(0.99-1.06)$ \\
Model 2 & $0.98(0.95-1.05)$ & $1.00(0.90-1.11)$ & $1.00(0.95-1.05)$ & & $1.03(1.00-1.07)$ & $1.07(1.00-1.15)$ & $1.02(0.99-1.06)$ \\
Model 3 & $1.00(0.96-1.05)$ & $1.00(0.90-1.11)$ & $1.01(0.95-1.06)$ & & $1.02(0.99-1.06)$ & $1.06(0.98-1.14)$ & $1.02(0.98-1.05)$ \\
\hline
\end{tabular}

${ }^{*} \mathrm{p}<0.05,{ }^{\dagger} \mathrm{p}<0.01,{ }^{\ddagger} \mathrm{p}<0.001$ by complex sample logistic regression. Model 1=Unadjusted, Model $2=$ Model 1+age, gender and education, Model 3=Model 2+WHODAS score and dementia status. WHODAS: World Health Organization Disability Assessment Schedule

ing $^{21}$ and is a parameter for the nutritional assessment of the elderly. ${ }^{23}$ Mediterranean dietary patterns and nutritional components (e.g., sufficient vitamin E, vitamin C, flavonoids, and vitamin $\mathrm{E}$ and lower vitamin $\mathrm{D}$ ) are related to the prevention or risk of dementia. ${ }^{34,35}$ These elements may have some association with the down-regulation of the key pathophysiological pathways involved in the development of dementia, including amyloid deposition, neurofibrillary degeneration, synapse loss, inflammation, increased oxidative stress, defects in mitochondrial function and cellular energy production, loss of vascular integrity, and neuronal injury. ${ }^{34}$

Small upper arm circumference may also reflect decreased physical activity. ${ }^{36}$ For example, sarcopenia is associated with lean body mass and lower physical activity levels. The relationship between weight loss in dementia and sarcopenia is unclear, but it might share common mechanisms, such as changes in hormonal status or inflammation. It is plausible that neurodegeneration in the central nervous system has detrimental effects on the peripheral nervous system. For example, changes in the activity of the neuromuscular junction may result in tone reduction and muscle atrophy. It follows from this that dementia may initiate or exacerbate sarcopenia. ${ }^{15}$

The associations between upper arm circumference and dementia were stronger in women than in men. The gender interaction may be explained by the different life environments of this generation. The preference for the male children was highly prevalent at the time when these participants were growing up, and it was common for parents to provide education and/or nutrition preferentially to men, particularly in families with lower socioeconomic status. Consistent with this, less education was also more strongly associated with dementia in women compared with in men. ${ }^{37}$

Unlike upper arm circumference, thigh circumference was less strongly associated with dementia. Some researchers have reported that smaller thigh circumference is related to the aging of skeletal muscle. ${ }^{38}$ However, Overend and colleagues $^{39}$ reported that the cross-sectional area of the thighs of elderly men is not different from that of young men; however, they found that muscle was decreased and fat was increased in the thighs of elderly men. Elderly women who engaged in strength and endurance training focused on the thighs showed reduced intramuscular fat and hypertrophied muscles. ${ }^{40}$ These characteristics of the thigh prevent a close association between thigh circumference and nutritional status or physical activity.

In our study, no association was found between anthropometric measures and depression. Some older adults suffering from depression had a poor appetite, but others reported increased appetite and weight gain. Increased appetite is another symptom of depression. Many studies have reported that obese people are more likely to be depressed than people of normal weight. ${ }^{41-43}$ However, many other studies have reported that nutritional deficit and decreased physical activity are associated with depression. Further research is required to clarify this matter.

The limitations of this study are related to its cross-sectional design in that conclusions about the direction of causality cannot be reached. As dementia is determined by syndrome diagnosis, it has various causes and thus, it is classified into subtypes. However our study used 10/66 dementia diagnostic algorithm which diagnoses the dementia as a whole, so it could not distinguish dementia with reversible course such as normal pressure hydrocephalus or others which can affect the result by themselves such as stroke. Furthermore, although many confounding factors were assessed, many other factors were neglected. For example, physical activity and dietary pattern are potentially important considerations that were not measured comprehensively in this study. Anthropometric measurements were taken using a tape measure, which was non-invasive and convenient for use with patients with dementia and depression. However, it would have been more helpful to use computerized tomography or magnetic resonance imaging to accurately define the composition of the upper arm and thigh.

The strength of this study involves in its large, communitybased population drawn from a well-validated database and the fact that it evaluated both dementia and depression. Depression is a known risk factor for dementia in the elderly, and it is sometimes referred to as 'psedodementia." Furthermore, many older adults with dementia also suffer from depression.

As mentioned earlier, dementia and depression are serious mental illnesses in older adults that are associated with an immense disease burden. In the case of dementia, recent research 
has emphasized the need for early detection and early prevention. Biomarkers, such as anthropometry, which is noninvasive and cost-effective, hold great potential for facilitating the early detection of dementia. For this reason, further research into the relationship between anthropometric measurements and mental illnesses among elderly individuals is required.

\section{Acknowledgments}

This work was funded by a grant from the Korean Health Technology R\&D Project, Ministry of Health \& Welfare, Republic of Korea (HI12 C0003).

\section{REFERENCES}

1. Park JH, Eum JH, Bold B, Cheong HK. Burden of disease due to dementia in the elderly population of Korea: present and future. BMC Public Health 2013;13:293.

2. Tai SY, Huang SW, Hsu CL, Yang CH, Chou MC, Yang YH. Screening dementia in the outpatient department: patients at risk for dementia. Sci World J 2014;2014:138786.

3. Beydoun MA, Beydoun HA, Gamaldo AA, Teel A, Zonderman AB, Wang Y. Epidemiologic studies of modifiable factors associated with cognition and dementia: systematic review and meta-analysis. BMC Public Health 2014;14:643.

4. Norton S, Matthews FE, Barnes DE, Yaffe K, Brayne C. Potential for primary prevention of Alzheimer's disease: an analysis of populationbased data. Lancet Neurol 2014;13:788-794.

5. Singh S, Mulley GP, Losowsky MS. Why are Alzheimer patients thin? Age Ageing 1988;17:21-28.

6. White $\mathrm{H}$, Pieper $\mathrm{C}$, Schmader K. The association of weight change in Alzheimer's disease with severity of disease and mortality: a longitudinal analysis. J Am Geriatr Soc 1998;46:1223-1227.

7. Shatenstein B, Kergoat MJ, Nadon S. Anthropometric changes over 5 years in elderly Canadians by age, gender, and cognitive status. J Gerontol A Biol Sci Med Sci 2001;56:M483-M488.

8. Gustafson DR, Bäckman K, Waern M, Östling S, Guo X, Zandi P, et al. Adiposity indicators and dementia over 32 years in Sweden. Neurology 2009;73:1559-1566.

9. Knopman DS, Edland SD, Cha RH, Petersen RC, Rocca WA. Incident dementia in women is preceded by weight loss by at least a decade. Neurology 2007; 69:739-746.

10. Stewart R, Masaki K, Xue QL, Peila R, Petrovitch H, White LR, et al. A 32 -year prospective study of change in body weight and incident dementia: the Honolulu-Asia Aging Study. Arch Neurol 2005;62:55-60.

11. Gillette Guyonnet S, Abellan Van Kan G, Alix E, Andrieu S, Belmin J, Berrut G, et al. IANA (International Academy on Nutrition and Aging) Expert Group: weight loss and Alzheimer's disease. J Nutr Health Aging 2007;11:38-48.

12. Doherty TJ. Invited review: aging and sarcopenia. J Appl Physiol (1985) 2003;95:1717-1727.

13. Roubenoff R. Sarcopenia: effects on body composition and function. J Gerontol A Biol Sci Med Sci 2003;58:1012-1017.

14. Pilleron S, Jesus P, Desport JC, Mbelesso P, Ndamba-Bandzouzi B, Clement JP, et al. Association between mild cognitive impairment and dementia and undernutrition among elderly people in Central Africa: some results from the EPIDEMCA (Epidemiology of Dementia in Central Africa) programme. Br J Nutr 2015;114:306-315.

15. Taylor CL, Albanese E, Stewart R. The association of dementia with upper arm and waist circumference in seven low- and middle-income countries: the 10/66 cross-sectional surveys. J Gerontol A Biol Sci Med Sci 2012;67:897-904.

16. Liu LK, Lee WJ, Liu CL, Chen LY, Lin MH, Peng LN, et al. Age-related skeletal muscle mass loss and physical performance in Taiwan: implications to diagnostic strategy of sarcopenia in Asia. Geriatr Gerontol Int 2013;13:964-971.

17. Serby M, Yu M. Overview: depression in the elderly. Mt Sinai J Med 2003;70:38-44.

18. Morley JE. Anorexia, sarcopenia, and aging. Nutrition 2001;17:660663.

19. Benton D, Donohoe RT. The effects of nutrients on mood. Public Health Nutr 1999;2:403-409.

20. Rogers PJ. A healthy body, a healthy mind: long-term impact of diet on mood and cognitive function. Proc Nutr Soc 2001;60:135-143.

21. Gavriilidou NN, Pihlsgard M, Elmstahl S. Anthropometric reference data for elderly Swedes and its disease-related pattern. Eur J Clin Nutr 2015;69:1066-1075.

22. Report of a WHO Expert Committee. Physical Status: the Use and Interpretation of Anthropometry. Geneva: WHO; 1995.

23. Wijnhoven HA, van Bokhorst-de van der Schueren MA, Heymans MW, de Vet HC, Kruizenga HM, Twisk JW, et al. Low mid-upper arm circumference, calf circumference, and body mass index and mortality in older persons. J Gerontol A Biol Sci Med Sci 2010;65:1107-1114.

24. Prince M, Acosta D, Chiu H, Scazufca M, Varghese M; 10/66 Dementia Research Group. Dementia diagnosis in developing countries: a cross-cultural validation study. Lancet 2003;361:909-917.

25. Kim JM, Stewart R, Prince M, Shin IS, Yoon JS. Diagnosing dementia in a developing nation: an evaluation of the GMS-AGECAT algorithm in an older Korean population. Int J Geriatr Psychiatry 2003;18:331336.

26. Kim JM, Kim SW, Shin IS, Zheng TJ, Yoon JS. Development of Korean version of community screening interview for dementia (CSID-K). J Korean Neuropsychiatr Assoc 2004;43:445-451.

27. American Psychiatric Association. Diagnostic and Statistical Manual of Mental Disorders DSM-IV-TR Fourth Edition (Text Revision). Washington, DC: American Psychiatric Association; 2000.

28. McCullagh CD, Craig D, McIlroy SP, Passmore AP. Risk factors for dementia. Adv Psych Treatment 2001;7:24-31.

29. Kim JM, Stewart R, Glozier N, Prince M, Kim SW, Yang SJ, et al. Physical health, depression and cognitive function as correlates of disability in an older Korean population. Int J Geriatr Psychiatry 2005;20:160167.

30. Burns JM, Johnson DK, Watts A, Swerdlow RH, Brooks WM. Reduced lean mass in early Alzheimer disease and its association with brain atrophy. Arch Neurol 2010;67:428-433.

31. Sparks DL, DeKosky ST, Markesbery WR. Alzheimer's disease. Aminergic-cholinergic alterations in hypothalamus. Arch Neurol 1988;45: 994-999.

32. Grundman M. Weight loss in the elderly may be a sign of impending dementia. Arch Neurol 2005;62:20-22.

33. Peila R, Rodriguez BL, White LR, Launer LJ. Fasting insulin and incident dementia in an elderly population of Japanese-American men. Neurology 2004;63:228-233.

34. Swaminathan A, Jicha GA. Nutrition and prevention of Alzheimer's dementia. Front Aging Neurosci 2014;6:282.

35. Cao L, Tan L, Wang HF, Jiang T, Zhu XC, Lu H, et al. Dietary patterns and risk of dementia: a systematic review and meta-analysis of cohort studies. Mol Neurobiol 2016;53:6144-6154.

36. Goodpaster BH, Carlson CL, Visser M, Kelley DE, Scherzinger A, Harris TB, et al. Attenuation of skeletal muscle and strength in the elderly: The Health ABC Study. J Appl Physiol (1985) 2001;90:2157-2165.

37. Kim JM, Stewart R, Shin IS, Yoon JS. Limb length and dementia in an older Korean population. J Neurol Neurosurg Psychiatry 2003;74:427432.

38. Frontera WR, Hughes VA, Fielding RA, Fiatarone MA, Evans WJ, Roubenoff R. Aging of skeletal muscle: a 12-yr longitudinal study. J Appl Physiol 2000;88:1321-1326.

39. Overend TJ, Cunningham DA, Paterson DH, Lefcoe MS. Thigh com- 
position in young and elderly men determined by computed tomography. Clin Physiol 1992;12:629-640.

40. Sipilä S, Suominen H. Effects of strength and endurance training on thigh and leg muscle mass and composition in elderly women. J Appl Physiol (1985) 1995;78:334-340.

41. Luppino FS, de Wit LM, Bouvy PF, Stijnen T, Cuijpers P, Penninx BW, et al. Overweight, obesity, and depression: a systematic review and me- ta-analysis of longitudinal studies. Arch Gen Psychiatry 2010;67:220229.

42. de Wit L, Luppino F, van Straten A, Penninx B, Zitman F, Cuijpers P. Depression and obesity: a meta-analysis of community-based studies. Psychiatry Res 2010;178:230-235.

43. Stunkard AJ, Faith MS, Allison KC. Depression and obesity. Biol Psychiatry 2003;54:330-337. 